\title{
THAM $v$. sodium bicarbonate in idiopathic respiratory distress syndrome ${ }^{\star}$
}

\author{
P. K. J. vaN VLIET and J. M. GUPTA \\ From the School of Paediatrics, Prince of Wales Hospital, University of New South Wales, Australia
}

van Vliet, P. K. J., and Gupta, J. M. (1973). Archives of Disease in Childhood, 48, 249. THAM $v$. sodium bicarbonate in idiopathic respiratory distress syndrome. Two buffers (sodium bicarbonate and THAM) were used in a controlled trial for treatment of severe idiopathic respiratory distress syndrome. The results indicate that THAM is marginally superior to sodium bicarbonate. 1 infant died as a result of direct toxic effect of THAM because of inadvertent administration of a hyperosmolar solution of THAM. Blood gas analysis indicated that THAM caused a rise in $\mathrm{PO}_{2}$ in a number of cases (7 out of 18), and a fall in $\mathrm{PCO}_{2}$ in 13 out of 21 cases where blood gas determinations had been done before and after treatment. In contrast, bicarbonate caused no change in $\mathrm{Po}_{2}$ and a rise in $\mathrm{Pco}_{2}$ in 5 of 16 cases where blood gas determinations had been carried out before and after treatment. Apnoea due to THAM administration was not encountered. The incidence of intraventricular haemorrhage was not different in the 2 groups.

In spite of intensive research over the past 20 years, the aetiology of the idiopathic respiratory distress syndrome (RDS) still remains unknown. However, the pathophysiological disturbances are now well understood. As the condition is self limiting, treatment is aimed at correction of these pathophysiological disturbances (hypoxaemia and acidosis) by the administration of oxygen and buffers. The two commonly used buffers are trishydroxymethyl-amino-methane (THAM) and sodium bicarbonate. Theoretically, THAM appears to be superior as it is effective equally in a 'closed' or 'open' system, though it has the disadvantages of causing respiratory depression, hypoglycaemia, and hyperkalaemia (Nahas, 1963; Strauss, 1968). A comparative trial to determine the efficiency of these two buffers in the treatment of severe idiopathic RDS has not been reported. The present study was undertaken to determine which of these two buffers was safer and more valuable in the management of these patients.

\section{Materials and methods}

The subjects of this study were treated at the Royal Hospital for Women or the Prince of Wales Hospital. The infants treated at the Royal Hospital for Women were born at that hospital, whereas the infants at the

Received 7 August 1972.

^Work done by a support from N.H.M.R.C. Grant.
Prince of Wales Hospital were referred from other centres. The diagnosis of idiopathic RDS was made on clinical signs and symptoms (Gupta, Dahlenburg, and Davis, 1967 ), and was confirmed by chest $x$-ray (Donald and Steiner, 1953). Babies who failed to achieve an arterial oxygen tension of more than $100 \mathrm{mmHg}$ in an environmental oxygen of 90 to $100 \%$ within the first 12 hours of life were considered to have severe RDS, and were randomly treated with either molar sodium bicarbonate solution or 0.3 molar THAM (3.6\% solution). The $p \mathrm{H}$ of the THAM solution had been adjusted to approximately 8.7 at $37^{\circ} \mathrm{C}$ by admixture with its hydrochloride. The dosages used are shown in Table I. Base therapy was discontinued if the $p \mathrm{H}$ was above $7 \cdot 40$.

The average age of entry to the trial of infants born at the Royal Hospital for Women who were treated with sodium bicarbonate and THAM was $\mathbf{7 \cdot 9}$ hours (range 4 to $11 \frac{1}{2}$ hours) and $6 \cdot 1$ hours (range 4 to 10 hours),

TABLE I

Dosage of $\mathrm{NaHCO}_{3}$ (molar solution) and THAM $(0 \cdot 3$ molar solution $)$

Initial dose $(\mathrm{ml})$
$0.3 \times$ birthweight $(\mathrm{kg}) \times 0.5$ base deficit
Followed by
$5 \mathrm{ml} / 100 \mathrm{ml}$ in i.v. infusion $\star$ if $p \mathrm{H} 7 \cdot 31-7 \cdot 40$
$10 \mathrm{ml} / 100 \mathrm{ml}$ in i.v. infusion if $p \mathrm{H} 7 \cdot 21-7 \cdot 30$
$15 \mathrm{ml} / 100 \mathrm{ml}$ in i.v. infusion if $p \mathrm{H} 7 \cdot 11-7 \cdot 20$
$20 \mathrm{ml} / 100 \mathrm{ml}$ in i.v. infusion if $p \mathrm{H} 7 \cdot 01-7 \cdot 10$

$\star 60 \mathrm{ml} / \mathrm{kg}$ of $10 \%$ dextrose daily. 
Complete details of 50 infants trä.

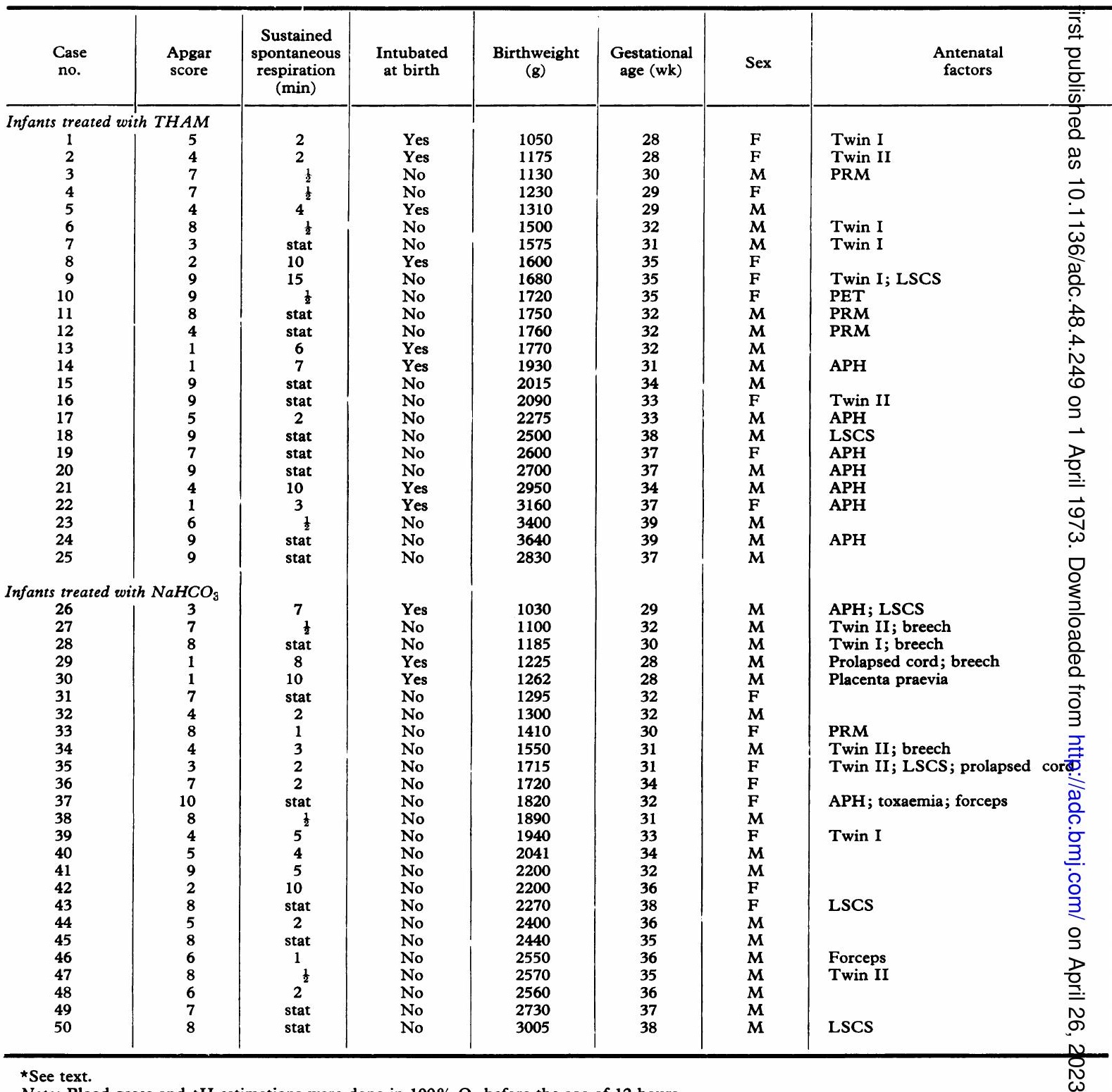

Note: Blood gases and $\mathrm{pH}$ estimations were done in $100 \% \mathrm{O}_{2}$ before the age of 12 hours.

PRM, premature rupture of membranes; LSCS, lower segment caesarian section; PET, pre-eclamptic toxaemia; APH, antepartum haemorhag HMD, hyaline membrane disease; IVH, intraventricular haemorrhage; PDA, persistent ductus arteriosus; stat, immediate.

respectively. The corresponding age of entry into the trial of infants admitted to the Prince of Wales Hospital was 8.5 hours (range 7 to 12 hours) and $9 \cdot 2$ hours (range 5 to 12 hours), respectively. No infant had received any base therapy (other than for resuscitation at birth) before admission to the trial.
Blood gases were monitored every 4 to 6 hours for the first 24 to $\mathbf{4 8}$ hours, and less frequently thereafter. The arterial blood was either obtained by an indwelling umbilical artery catheter or frequent radial artery punctures. The environmental oxygen was regulated to achieve an arterial $\mathrm{Po}_{2}$ of 60 to $90 \mathrm{mmHg}$. In both 
rith $\mathrm{THAM}(25)$ and $\mathrm{NaHCO}_{3}(25)$

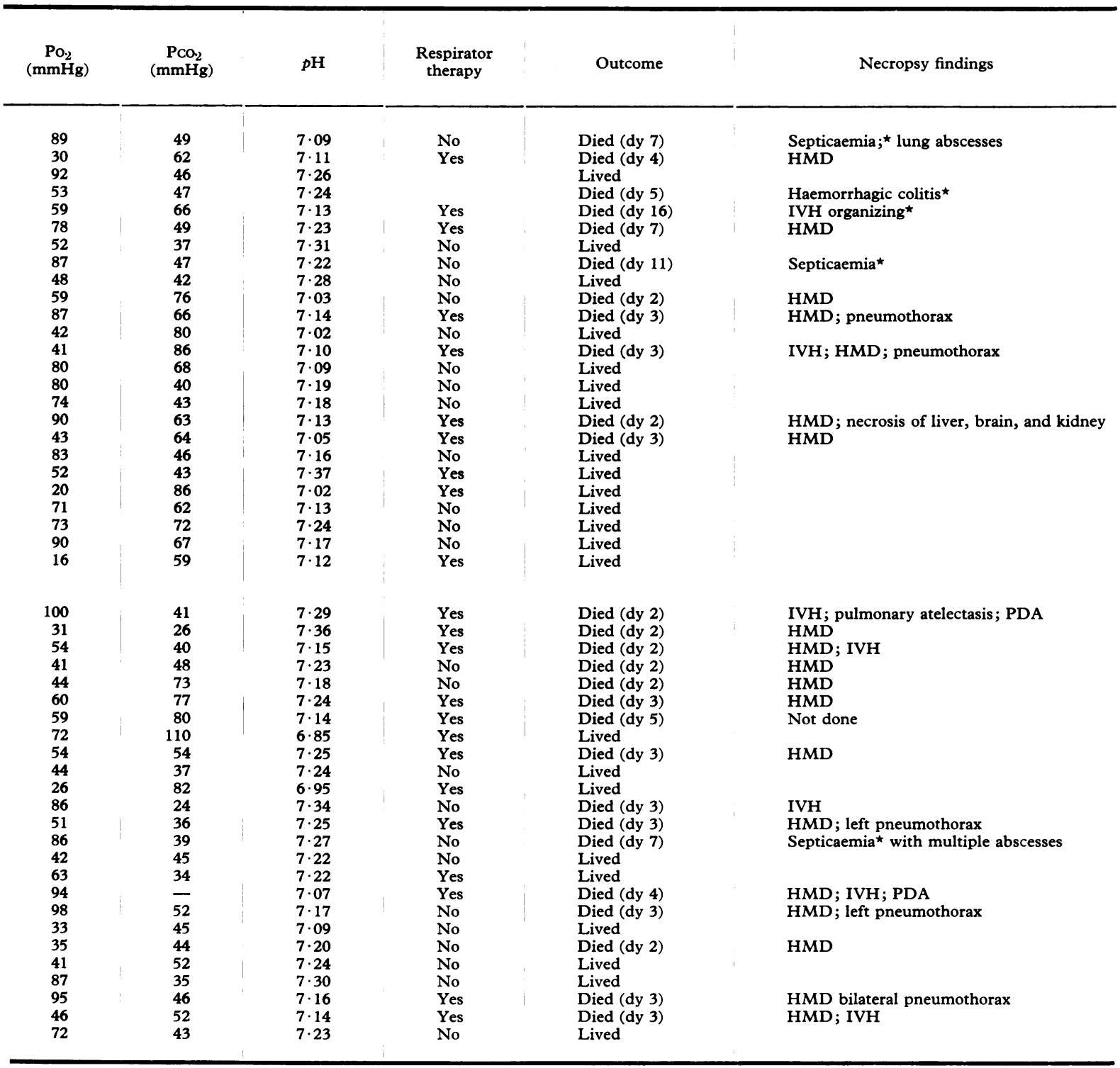

groups of infants respirator therapy was instituted if the infant failed to maintain adequate ventilation (apnoeic spells not responding to stimulation, arterial $\mathrm{Po}_{2}$ less than $30 \mathrm{mmHg}$ ). All infants were given $10 \%$ dextrose intravenously at the rate of $60 \mathrm{ml} / \mathrm{kg}$ per $24 \mathrm{hr}$ until oral feeding was started which was usually within
24 to 48 hours of birth. Necropsy was carried out in all but one of the infants who died.

\section{Results}

Over a period of 3 years 50 newborn infants 
with severe idiopathic respiratory distress were studied. 25 of these infants were treated with sodium bicarbonate and 25 with THAM. The number of infants born at the Royal Hospital for Women, who were treated with sodium bicarbonate and THAM, were 14 and 11 , respectively. Table II shows details of the clinical features (Apgar score, onset of spontaneous respiration, resuscitation, birthweight, gestational period, sex, and antenatal factors, blood gas analysis in the first 12 hours in 90 to $100 \%$ environmental oxygen, the need for respirator therapy, outcome, and necropsy findings). It will be observed that the 2 groups of infants are similar, i.e. there was no bias regarding clinical features, blood gas analysis, or the institution of respirator therapy. These parameters are summarized in Tables III, IV, V, VI, and VII.

TABLE III

Distribution of birthweight of two groups

\begin{tabular}{c|c|c|c|c|c}
\hline $\begin{array}{c}\text { Birthweight } \\
(\mathrm{g})\end{array}$ & $\begin{array}{c}1001- \\
1500\end{array}$ & $\begin{array}{c}1501- \\
2000\end{array}$ & $\begin{array}{c}2001- \\
2500\end{array}$ & $>2500$ & Total \\
\hline THAM treated & 6 & 8 & 4 & 7 & 25 \\
NaHCO $_{3}$ treated & 8 & 6 & 6 & 5 & 25 \\
\hline
\end{tabular}

$\chi^{2}=0.653$ for 3 degrees of freedom, $0.9>P>0.7$.

TABLE IV

Distribution of gestational age of two groups

\begin{tabular}{l|r|r|r|r|r|r|r}
\hline $\begin{array}{c}\text { Gestational age } \\
\text { (wk) }\end{array}$ & $<30$ & $30-31$ & $32-33$ & $34-35$ & $36-37$ & $>37$ & Total \\
\hline $\begin{array}{c}\text { THAM } \\
\text { treated }\end{array}$ & 4 & 3 & 6 & 5 & 4 & 3 & 25 \\
$\begin{array}{c}\text { NaHCO }_{3} \\
\text { treated }\end{array}$ & 3 & 5 & 6 & 4 & 5 & 2 & 25 \\
\hline
\end{tabular}

$\chi^{2}=1 \cdot 256$ for 3 degrees of freedom, $0 \cdot 9>P>0 \cdot 7$.

TABLE V

Distribution by sex in two groups

\begin{tabular}{l|c|c}
\hline & Females & Males \\
\hline THAM treated & 9 & 16 \\
NaHCO $_{3}$ treated & 8 & 17 \\
\hline
\end{tabular}

$\chi^{2}=0.089$ for one degree of freedom, $0.9>P>0.7$.

TABLE VI

Initial blood gases and $\mathrm{pH}$ in two groups

\begin{tabular}{c|c|c|c}
\hline Group & $\mathrm{PaO}_{2}(\mathrm{mmHg})$ & $\mathrm{PaCO}_{2}(\mathrm{mmHg})$ & $p \mathrm{H}$ \\
\hline THAM treated & 64 & 59 & $7 \cdot 16$ \\
NaHCO $_{3}$ treated & 61 & 49 & $7 \cdot 17$ \\
\hline
\end{tabular}

TABLE VII

Outcome of respirator therapy in two groups

\begin{tabular}{l|c|c}
\hline \multicolumn{1}{c|}{ Group } & Lived & Died \\
\cline { 2 - 3 } THAM treated & $4^{\star}$ & 6 \\
$\mathrm{NaHCO}_{3}$ treated & 3 & 10 \\
\hline
\end{tabular}

$\chi^{2}=1.53$ for one degree of freedom, $0.3>\mathrm{P}>0.1$.

$\star$ One of these infants died later from an unrelated cause (see Table II and text).

Of the babies treated with THAM, 14 survived. Of the 11 infants who died, death was due to respiratory insufficiency in 7 . The other 4 had recovered from their respiratory problems (as determined by clinical features and blood gas analysis), and in 2 of those death was due to septicaemia. In the third, death occurred after an exchange transfusion and necropsy revealed haemorrhagic colitis, and the fourth who died (aged 2 weeks) was found at necropsy to have an organizing intraventricular haemorrhage. It therefore appears that 18 infants in the THAM-treated group recovered from their respiratory problems. In the infants treated with sodium bicarbonate, 15 died from respiratory insufficiency: death occurred in 1 as a result of septicaemia. These results are presented in Tables VIII and IX which show

TABLE VIII

Primary cause of death found at necropsy

\begin{tabular}{|c|c|c|}
\hline Cause of death & THAM treated & $\mathrm{NaHCO}_{3}$ treated \\
\hline $\begin{array}{l}\text { Intraventricular haemorrhage } \\
\text { Respiratory insufficiency due } \\
\text { to pneumothorax and } \\
\text { HMD } \\
\text { Respiratory insufficiency due } \\
\text { to HMD } \\
\text { Septicaemia } \\
\text { Bowel perforation }\end{array}$ & $\begin{array}{l}2 \\
4 \\
2 \\
1\end{array}$ & $\begin{array}{l}5+ \\
3 \\
6 \\
1 \\
-\end{array}$ \\
\hline
\end{tabular}

^Includes 1 infant who also had respiratory insufficiency due to HMD.

†These infants also had respiratory insufficiency due to HMD. HMD, hyaline membrane disease.

TABLE IX

Outcome of treatment in the two groups

\begin{tabular}{c|c|c}
\hline Group & $\begin{array}{c}\text { Recovered from } \\
\text { respiratory distress }\end{array}$ & $\begin{array}{c}\text { Died from } \\
\text { respiratory distress }\end{array}$ \\
\hline THAM treated $^{\text {NaHCO }}$ treated & $18^{\star}$ & 7 \\
\hline
\end{tabular}

$\chi^{2}=5 \cdot 2$ for one degree of freedom, $0.05>P>0.02$.

*Includes 4 infants who died from other causes.

tIncludes 1 infant who died from another cause. 
that recovery from severe RDS was significantly better in the THAM-treated group. However, if one considers mortality irrespective of the cause of death in both groups, there is no significant difference in survival rate.

We analysed our results in relation to birthweight categories, namely 1001 to $1500 \mathrm{~g}, 1501$ to $2000 \mathrm{~g}$, 2001 to 2500 , and more than $2500 \mathrm{~g}$. The recovery rate of each of these weight groups is shown in Table X. It will be noted that more of the babies

TABLE X

Birthweight of infants who recovered

\begin{tabular}{l|c|c|c|c|c}
\hline \multicolumn{1}{c|}{ Birthweight } & $\begin{array}{c}1001- \\
1500\end{array}$ & $\begin{array}{c}1501- \\
2000\end{array}$ & $\begin{array}{l}2001- \\
2500\end{array}$ & $>2500$ & Total \\
\hline THAM treated & 4 & 5 & 2 & 7 & 18 \\
NaHCO $_{3}$ treated & 1 & 3 & 3 & 3 & 10 \\
\hline
\end{tabular}

under $2000 \mathrm{~g}$ treated with THAM (9 out of 14) recovered than of those treated with sodium bicarbonate (4 out of 14 recovered). However, the difference was statistically not significant $\left(\chi^{2}=3 \cdot 59\right)$. There were 33 male and 17 female infants in this trial. There was no difference in distribution and survival rate of the two sexes in the various weight groups. As indicated earlier, some of the babies were offered ventilatory assistance. Table VII shows the number of infants who received ventilatory assistance in each group and the outcome. Once more there was no bias, and the survival rate in the 2 groups that received ventilatory assistance is not different.

\section{Discussion}

The severity of idiopathic respiratory distress is variable. The condition may be transitory (Sundell et al., 1971), the infant in such cases recovering within 24 to 36 hours; or mild, where the infant requires small amounts of added oxygen for 3 to 4 days; or severe, in which case the infant progressively requires increasing amounts of oxygen and, in spite of intensive alkali therapy, may continue to develop progressive respiratory failure. It is, therefore, not surprising that in a disease of such variability, various treatments have been instituted (Usher, 1963; Troelstra et al., 1964; Lancet, 1964; Hutchison et al., 1962) and success has been reported with each form of treatment. Treatment with oxygen and alkalis (Usher, 1963; Troelstra, et al., 1964) appears to be rational because it corrects the basic pathophysiological disturbances. Boston, Geller, and Smith (1966) have shown that infants who fail to achieve arterial oxygen tension of more than $100 \mathrm{mmHg}$ in an environmental oxygen of 90 to $100 \%$ have a mortality rate of $81 \%$. The mortality rate in the group treated with sodium bicarbonate in our trial was $64 \%$ and compares favourably with the report of Boston et al. (1966). However, this favourable comparison is not surprising as we were using respirators in addition to oxygen and bicarbonate in the management of these patients. In contrast, the mortality rate from the disease in the THAM-treated group was $28 \%$ though, as emphasized earlier, 4 of these infants died subsequently due to unrelated conditions. Troelstra et al. (1964) reported a mortality rate of $43 \%$ in babies with severe idiopathic RDS who were treated with THAM (but their criteria for the diagnosis of severe RDS are not clear). It appears that the use of THAM in the management of severe idiopathic RDS is to be preferred to sodium bicarbonate.

Ventilatory assistance was given to 13 of the 25 babies who were treated with sodium bicarbonate and 10 of the 25 THAM-treated babies. Of these there were 3 survivors in the group treated with sodium bicarbonate as compared to 4 treated with THAM. There was no bias in regard to ventilatory assistance offered in each group of babies. It is interesting to note that if the respiratory assistance had been withheld in both groups, and assuming that all of the survivors would have died, the mortality in the 2 groups of patients approaches that of Boston et al. (1966) and Troelstra et al. (1964), respectively.

Detailed analysis of the trial reported in this paper and a critical appraisal of the data presented in Table II suggest that the 2 groups are not comparable in regard to $\mathrm{PCO}_{2}$ (13 infants in the bicarbonate-treated group had a $\mathrm{PCO}_{2}$ of less than $45 \mathrm{mmHg}$ compared to 5 in the THAM-treated group), $p \mathrm{H}$ (11 infants had a $p \mathrm{H}$ of less than $7 \cdot 20$ in the bicarbonate-treated group compared to 17 infants in the THAM-treated group), and the amount of base given (molar bicarbonate compared to 0.3 molar THAM). It is obvious that the THAM-treated group was heavily weighted against in terms of severity of the illness (if one accepts $\mathrm{PcO}_{2}$ and $p \mathrm{H}$ as criteria of severity of illness), yet the amount of base given was less than bicarbonate. We have purposely not taken these factors into account in the final assessment of our results because we regard $p \mathrm{H}$ and $\mathrm{PCO}_{2}$ as poor indicators of the final outcome. Ostrea and Odell (1972) have drawn attention to the deleterious effects of molar bicarbonate in a 'closed system', and it might be argued that the better results obtained 
in the THAM-treated group may be due to the deleterious effects of molar bicarbonate rather than the benefit of THAM.

THAM is known to cause respiratory depression in experimental animals. Roberton (1970) reported the occurrence of apnoeic spells within 2 minutes of administering THAM to newborn infants. On the other hand, Gupta et al. (1967) encountered this problem in only 1 case. As Roberton has indicated, the explanation may lie in the fact that, whereas Gupta et al. (1967) used 0.3 molar THAM, some of his patients received a solution that was of much higher concentration. In our series of 25 patients we did not encounter this problem, and this is mainly related to the method of administration and concentration of solution of THAM (see above). We would also like to emphasize that we did not observe any changes in respiratory rate or respiratory excursion soon after administering the initial dose of THAM.

Roberton (1970) has suggested that THAM might have caused an increase in death rate in his series by causing apnoea either directly or by increasing the intraventricular haemorrhage rate. Table VIII shows the necropsy findings in the 22 out of 23 infants who died. Our results strongly suggest that there is no increase in the incidence of intraventricular haemorrhage in babies treated with THAM. Death was directly attributed to the administration of THAM in 1 infant who was inadvertently given a solution of 1.5 molar $(18 \%)$ THAM. The cause of death in this infant was haemorrhagic necrosis in the left lobe of the liver, extensive cortical haemorrhages in the kidney, and extensive neuronal damage in the brain. There is little doubt that some of the pathological changes in this infant were related to hypoxia. However, necrosis of the liver has been observed by Goldenberg, Wiegenstein, and Hopkins (1968) and Brinkman et al. (1961) with the use of hyperosmolar solution of THAM. As similar lesions have been described after the use of hyperosmolar solutions of sodium bicarbonate (Adamsons et al., 1963), it appears that the liver and renal damage may be related to the hyperosmolarity of the solution rather than to a direct toxic effect of THAM.

Hypoglycaemia and hyperkalaemia have been reported with the use of THAM in experimental animals (Bennett and Tarail, 1961). Hypoglycaemia is a recognized biochemical disturbance in newborn babies with idiopathic RDS (Usher, 1961). In our series all babies were routinely monitored with Dextrostix and there were no babies who had either clinical or biochemical evidence of hypoglycaemia. We did not routinely perform estima- tions of serum electrolytes, but in those babies who had serum potassium estimations we did not find any values above $6 \mathrm{mEq} / \mathrm{l}$.

Gupta (1965) and Gupta et al. (1967) have reported a rise in $\mathrm{PaO}_{2}$ after administration of THAM in infants with idiopathic RDS. Similar results have been reported by Russell and Cotton (1968) with the use of sodium bicarbonate. In our trial, of the 16 cases where blood gas analysis had been done within 30 to 60 minutes before and after the initial dose of sodium bicarbonate, no appreciable change was noticeable in $\mathrm{Po}_{2}$. On the other hand, in the 18 infants of the THAM-treated group in whom pre- and post-treatment blood gas measurement had been carried out, there was a rise in $\mathrm{Po}_{2}$ in 7 cases, a fall in $\mathrm{Po}_{2}$ in 1 , and no appreciable change in the other 10 (Table XI).

\section{TABLE XI}

Effect on blood gas tensions of buffer administration

\begin{tabular}{|c|c|c|c|c|}
\hline & \multicolumn{2}{|c|}{$\begin{array}{l}\text { Effect on } \mathrm{Po}_{2} \\
\text { (no. of cases) }\end{array}$} & \multicolumn{2}{|c|}{$\begin{array}{c}\text { Effect on } \mathrm{PCO}_{2} \\
\text { (no. of cases) }\end{array}$} \\
\hline & $\begin{array}{l}\text { THAM } \\
\text { treated }\end{array}$ & $\underset{\text { treated }}{\mathrm{NaHCO}_{3}}$ & $\begin{array}{l}\text { THAM } \\
\text { treated }\end{array}$ & $\underset{\text { treated }}{\mathrm{NaHCO}_{3}}$ \\
\hline $\begin{array}{l}\text { Rise } \\
\text { Fall } \\
\text { No change } \\
\text { Not done }\end{array}$ & $\begin{array}{r}7 \\
1 \\
10 \\
7\end{array}$ & $\frac{-}{16}$ & $\begin{array}{r}-13 \\
8 \\
4\end{array}$ & $\begin{array}{l}\frac{5}{10} \\
10\end{array}$ \\
\hline
\end{tabular}

THAM is supposed to be theoretically superior to sodium bicarbonate in the treatment of acidosis in idiopathic RDS because of its ability to act in a closed system. We therefore looked at our blood gas results in relation to changes in $\mathrm{PCO}_{2}$ after the administration of the initial dose of the two buffers. It was found that of the 16 cases treated with sodium bicarbonate in which blood gas analysis had been done before and after treatment (within 30 to 60 minutes), $\mathrm{Pco}_{2}$ rose in 5 cases and remained unchanged in 10. On the other hand, of the 21 cases treated with THAM in which $\mathrm{PcO}_{2}$ had been determined before and after treatment, $\mathrm{PcO}_{2}$ fell in 13 cases and remained unchanged in 8 cases (Table XI). Similar results have been reported by Gupta et al. (1967).

REFERENCES

Adamsons, K., Jr., Behrman, R., Dawes, G. S., Dawkins, M. J. R. James, L. S., and Ross, B. B. (1963). The treatment of acidosis with alkali and glucose during asphyxia in foetal rhesus monkeys. fournal of Physiology, 169, 679.

Bennett, T. E., and Tarail, R. (1961). The hypoglycaemic activity of 2-amino-2-hydroxymethyl-1, 3-propanediol. Annals of the New York Academy of Sciences, 92, 651. 
Boston, R. W., Geller, F., and Smith, C. A. (1966). Arterial blood gas tensions and acid-base balance in the management of the respiratory distress syndrome. Fournal of Pediatrics, 68, 74.

Brinkman, G. L., Brunswick, W. L., Whitehouse, F. W., James, L. S., and Ross, B. B. (1961). The use of 2-amino-2-hydroxymethyl-1, 3-propanediol in the correction of metabolic and respiratory acidosis. Annals of the New York Academy of Sciences, 92, 735.

Donald, I., and Steiner, R. E. (1953). Radiography in the diagnosis of hyaline membrane. Lancet, $2,846$.

Goldenberg, V. E., Wiegenstein, L., and Hopkins, G. B. (1968) Hepatic injury associated with Tromethamine. fournal of the American Medical Association, 205, 81.

Gupta, J. M. (1965). The effect of THAM on the oxygen tension of arterial blood in neonatal respiratory-distress syndrome. Lancet, 1, 734.

Gupta, J. M., Dahlenburg, G. W., and Davis, J. A. (1967). Changes in blood gas tensions following administration of amine buffer THAM to infants with respiratory distress syndrome. Archives of Disease in Childhood, $\mathbf{4 2}, 416$.

Hutchison, J. H., Kerr, M. M., McPhail, M. F. M., Douglas, T. A., Smith, G., Norman, J. N., and Bates, E. H. (1962). Studies in the treatment of the pulmonary syndrome of the newborn. Lancet, 2, 465.

Lancet (1964). Epsom salts for hyaline membrane disease. (Annotation.) Lancet, 2, 1110.

Nahas, G. G. (1963). The clinical pharmacology of THAM [tris (hydroxymethyl) aminomethane]. Clinical Pharmacology and Therapeutics, 4, 784.

Ostrea, E. M., and Odell, G. B. (1972). The influence of bicarbonate on blood $\mathrm{pH}$ in a 'closed system': clinical implications. fournal of Pediatrics, 80, 671 .
Roberton, N. R. C. (1970). Apnoea after THAM administration in the newborn. Archives of Disease in Childhood, 45, 206.

Russell, G., and Cotton, E. K. (1968). Effects of sodium bicarbonate by rapid injection and of oxygen in high concentration in respiratory distress syndrome of the newborn. Pediatrics, 41, 1063.

Strauss, J. (1968). Tris (hydroxymethyl) amino-methane (THAM): a pediatric evaluation. Pediatrics, 41, 667 .

Sundell, H., Garrott, J., Blankenship, W. J., Shepard, F. M., and Stahlman, M. T. (1971). Studies on infants with type II respiratory distress syndrome. Fournal of Pediatrics, 78, 754.

Troelstra, J. A., Jonxis, J. H. P., Visser, H. K. A., and Van der Vlugt, J. J. (1964). Metabolism and acid-base regulation in respiratory distress syndrome; treatment with tris-hydroxymethyl-amino methane (THAM). In Nutricia Symposium: the adaptation of the newborn infant to extra-uterine life, p. 185. Ed. by J. H. P. Jonxis, H. K. A. Visser, and J. A. Troelstra. Stenfert Kroese, Leiden.

Usher, R. (1961). Metabolic changes in respiratory distress syndrome of prematurity seen as a failure of somatic compensation for asphyxia. In Somatic Stability in the Newly Born, Ciba Symposium, p. 92. Ed. by G. E. W. Wolstenholme and M. O'Connor. Churchill, London.

Usher, R. (1963). Reduction of mortality from respiratory distress syndrome of prematurity with early administration of intravenous glucose and sodium bicarbonate. Pediatrics, 32, 966.

Correspondence to Associate Professor J. M. Gupta, Prince of Wales Hospital, Randwick, N.S.W. 2031, Australia. 